\title{
Computação material: um estudo sobre a atualização geométrica de elementos vazados na arquitetura
}

\author{
Material computation: a study about the geometric updating of screenwalls in architecture
}

\author{
SANTANA NETO, Ernesto José de \\ Universidade Católica de Pernambuco, Brasil \\ eneto.santana@gmail.com \\ SILVA, Robson Canuto da \\ Universidade Católica de Pernambuco, Brasil \\ robsoncanuto.arq@gmail.com
}

\begin{abstract}
This paper deals with geometric update strategies of cobogós, aiming to expand its energy efficiency based on material computation, a design approach that seeks to achieve greater architectural performance through the investigation of material properties, comprising four aspects that structure the paper: materiality, material structure, material performance and materialisation. Analysis in ceramic, the most common material in the manufacturing of cobogós, showed voronoi microstructure geometry in the material. Incorporating this logic to the development of a new geometry of cobogó results a slight increase of its thermal performance comparing with commercial cobogós.
\end{abstract}

Keywords: Material computation; Cobogó; Energy efficiency.

\section{Introdução}

A busca por controle climático do ambiente interno deu origem ao desenvolvimento de equipamentos elétricos de calefação e refrigeração do ar. A popularização e consequente uso excessivo desses equipamentos ampliou consideravelmente o consumo energético, tornando-se um dos responsáveis pelo aumento da emissão de gases causadores do efeito estufa. Segundo Hensel (2008), a invenção destes equipamentos causou um impacto na arquitetura, que vem paulatinamente perdendo elementos passivos de controle microclimático, dando lugar a ambientes enclausurados em redomas de vidro com temperatura homogênea. Tal processo deu origem a um paradigma espacial arquitetônico, ao criar uma dicotomia entre o interior e o exterior da edificação, diminuindo sua integração ambiental.

"Temos, portanto, herdado um incontestável paradigma espacial solipsista que é determinado e, por sua vez, determina a maneira como pensamos a modulação homogênea de ambientes quase hermeticamente fechados." (HENSEL, 2008, p. 49, tradução nossa).

Em contrapartida, estratégias passivas de amenização climática, amplamente utilizadas na tradição arquitetônica, como ventilação natural e proteção solar, frequentemente apresentam soluções sustentáveis de controle microclimático. Entretanto, a eficiência dessas estratégias já não pode mais ser garantida em determinados contextos ambientais, que impõem condições climáticas ainda mais restritivas acima de suas capacidades performativas, como apontam Frota; Schiffer (2001).
"Assim, localidades onde esse valor da temperatura externa média já é superior ao limite do conforto humano, ou seja, $2^{\circ} \mathrm{C}$, não é possível garantir, internamente às construções, temperaturas dentro da faixa de conforto apenas utilizandose de recursos naturais." (FROTA e SCHIFFER, 2001, p. 146).

Apesar de tais limitações, uma arquitetura adaptada ao clima no qual está inserida alcança maior racionalização energética, pois as soluções passivas adotadas são imprescindíveis para ampliar a eficiência e amenizar a utilização dos equipamentos elétricos (HOLANDA, 1976).

"Os estudos de adequação dos edifícios aos trópicos não perderão seu interesse na medida em que sejam desenvolvidos novos sistemas de condicionamento do ar. [...] uma vez que o dimensionamento dos equipamentos estará sempre dependente da maior ou menor proteção dos ambientes à radiação solar." (HOLANDA, 1976, p. 17).

Recentemente, o advento do design computacional, uma concepção projetual desenvolvida através da colaboração de processos computacionais (AHLQUIST; MENGES, 2011), vem possibilitando a atualização de estratégias passivas de controle microclimático no contexto contemporâneo (HENSEL, 2008). Neste cenário, a computação material, abordagem que busca integrar as propriedades dos materiais utilizados na construção ao processo de desenvolvimento da forma arquitetônica (OXMAN, 2012), apresenta-se como uma alternativa de grande potencial para esta atualização, pois ao estudar os comportamentos e variações formais dos materiais, frente a estímulos ambientais, pode-se utilizar dos conhecimentos oferecidos pela própria natureza para lidar com estratégias de redução energética. 
Uma estratégia passiva de amenização climática utilizada na arquitetura moderna brasileira é o cobogó, um sistema vazado usado como elemento de vedação e proteção com o intuito de permitir a ventilação e filtrar a incidência solar. $\mathrm{Na}$ região Nordeste do Brasil, a estratégia de vazar os muros com cobogós, defendida por Holanda (1976), mostrou-se como um instrumento de adaptação tropical das edificações.

O cobogó pode ter seu desempenho ampliado através da computação material, pois investigações acerca das propriedades do material tem potencial para fornecer informações a serem incorporadas na atualização geométrica do elemento em prol de maior eficiência energética, minimizando o uso de aparelhos elétricos e reassumindo seu papel de agente ambientalmente integrador.

\section{Computação Material}

A computação material é uma abordagem projetual baseada no estudo das propriedades do material para orientar a concepção arquitetônica (MENGES, 2012; OXMAN, 2012). Menges (2012) apresenta esta abordagem como um verdadeiro aproveitamento da matéria, pois através dela as capacidades do material transformam-se em objeto de pesquisa para geração da forma arquitetônica. De acordo com Achim Menges, a computação material é:

"Uma alternativa de abordagem projetual que desdobra a forma (Gestalt) específica do material, e suas capacidades performativas relacionadas, pela reconciliação da geração da forma (Form) e a materialização física [...] integrando a informação do material como um processo gerador da concepção projetual." (Menges, 2012, p. 17, tradução nossa).

Ainda segundo Menges (2014), uma pesquisa de computação material é desenvolvida a partir de quatro aspectos acerca do material trabalhado:

Materialidade - Estudo do material através de suas propriedades, visando à integração de tais informações ao processo de concepção;

Estrutura do material - Estudo das formas de organização dos componentes dentro do sistema microestrutural de um determinado material;

Desempenho do material - Estudo da responsividade do material frente às variações climáticas do ambiente no qual ele está inserido;

Materialização - Estudo dos meios de produção da forma arquitetônica, buscando conciliar o método de fabricação ao material trabalhado.

Oxman (2012) apresenta a computação material como uma abordagem desenvolvida ao longo de um conjunto de estratégias computacionais que integram a geometria, o material e a estrutura arquitetônica em busca de maior adequação ambiental. Por sua vez, um processo projetual que integre estas informações ao desenvolvimento da forma arquitetônica tem o potencial de ampliar exponencialmente o desempenho desejado para um objeto.

Deste modo, o emprego desta abordagem na concepção de cobogós pode ampliar seu desempenho através da investigação de propriedades de eficiência energética, encontradas nos materiais, integrada a processos digitais de análise, modelagem e fabricação, fornecendo assim uma alternativa eficaz para a geração de microclimas confortáveis.

\section{Cobogó Computacional}

Diante do exposto, foi utilizada a computação material para a pesquisa de um cobogó que atendesse às expectativas contemporâneas. Foi desenvolvida uma estratégia projetual, baseada em uma investigação material, que propiciasse a produção de um sistema vazado com desempenhos térmicos variados. Assim, foi utilizada uma metodologia baseada nos quatro aspectos da computação material.

\section{Materialidade}

O cobogó, ao longo do tempo, foi desenvolvido em diversos materiais, como o concreto, cerâmica e vidro. Dentre estes, a cerâmica merece um destaque, pois possui propriedades térmicas que favorecem a finalidade de controle climático.

Segundo a ABCERAM (2015), o termo "cerâmica compreende todos os materiais inorgânicos, não metálicos, obtidos geralmente após tratamento térmico em temperaturas elevadas.", podendo ter classificações diferentes segundo suas propriedades. O tipo de cerâmica mais utilizada na produção de cobogós é a cerâmica vermelha, esta cerâmica possui propriedades de isolamento térmico, durabilidade e resistência a altas temperaturas, e sua principal matéria-prima é a argila, material do qual deriva a argila expandida que possui um desempenho térmico ainda maior.

"A argila expandida é o produto obtido por aquecimento de alguns tipos de argila na temperatura em torno de $1200{ }^{\circ} \mathrm{C}$. Próximo desta temperatura, uma parte dos constituintes do material se funde, gerando uma massa viscosa, enquanto a outra parte se decompõe quimicamente, liberando gases que são incorporados por esta massa sinterizada, expandindo-a em até sete vezes o seu volume inicial." (W. G. Moravia et al., 2006, p. 193).

Trata-se de esferas cerâmicas, com micro poros internos, revestidas por uma casca. A argila expandida pode ser produzida em diferentes granulometrias e sua disposição em um espaço varia segundo estas diferenças.

\section{Estrutura do material}

Ao observar a estrutura formal da argila expandida em escala microscópica, percebe-se uma lógica de estruturação voronoi. O voronoi é um modelo matemático de decomposição do espaço através de células cuja distância entre seus vértices e seu centroide não excede a distância entre dois centroides (TRAN et al., 2009). Tal lógica se aplica 
tanto à superfície interna como a superfície externa da argila expandida (Figura 1).

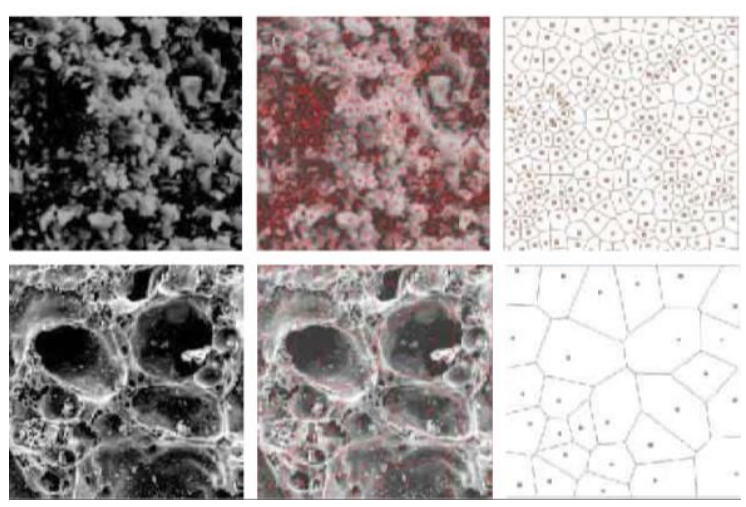

Figura 1: Estruturação voronoi da argila expandida.

Fonte: W. G. Moravia et al. (2006) / Estudos autorais

Em contrapartida, percebem-se lógicas euclidianas de decomposição do espaço nos padrões comerciais de cobogós, através de uma malha homogênea com aberturas idênticas em todos os pontos do sistema. Por sua vez, a decomposição voronoi gera malhas heterogêneas, proporcionando diferentes composições dentro do mesmo sistema (Figura 2), indicando que a utilização desta estrutura em sistemas vazados como o cobogó possibilita maior controle de variação da incidência solar.

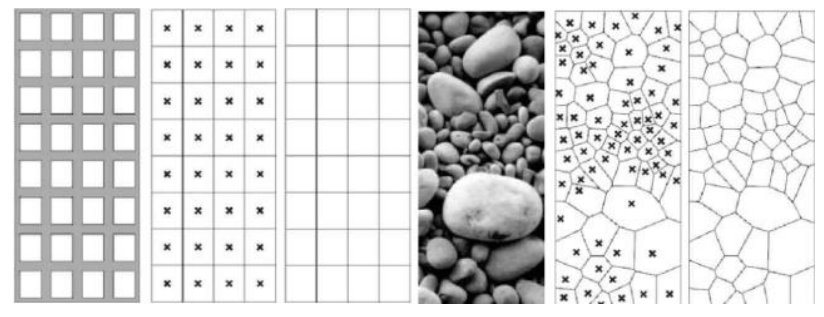

Figura 2: Malha homogênea do cobogó tradicional versus malha heterogênea da estrutura voronoi.

Fonte: SPLabor (2015) / Estudos autorais

\section{Desempenho do material}

A argila expandida é um material poroso, segundo Whitaker (1969), as principais propriedades de um material poroso são a porosidade, permeabilidade e condutividade térmica, tais características determinam o desempenho térmico do material.

Porosidade - Porcentagem de volume vazio presente em uma quantidade de material. É resultante da razão entre o volume de vazios e o volume total da amostra;

$$
\mathrm{n}=[\mathrm{Vv} /(\mathrm{V} \mathrm{v}+\mathrm{Vs})] .100
$$

$\mathrm{n}$ - porosidade (\%); Vv - volume de vazios $\left(\mathrm{m}^{3}\right) ; \mathrm{Vs}$ - volume seco $\left(m^{3}\right)$.
Permeabilidade - Capacidade de o material transmitir fluidos. É resultante da razão entre a multiplicação da espessura da amostra com a vazão final do fluido e a multiplicação da seção transversal da amostra, o tempo de escoamento do fluido e a carga hidráulica;

$$
\mathrm{k}=(\mathrm{Q} . \mathrm{L}) /(\text { A.t.h) (2) }
$$

k - coef. de permeabilidade $(\mathrm{cm} / \mathrm{s}) ; \mathrm{Q}$ - vazão do fluido no fim do percurso (cm/s); L - espessura da amostra $(\mathrm{cm})$; A - seção transversal da amostra $\left(\mathrm{cm}^{2}\right) ; \mathrm{t}$ - tempo de escoamento da água (s); $\mathrm{h}$ - carga hidráulica $(\mathrm{cm})$.

Condutividade térmica - Capacidade de o material transferir calor de um meio quente para um meio frio. É resultante da razão entre a multiplicação da espessura unitária da amostra com a variação de calor e a multiplicação da seção transversal unitária da amostra, o intervalo de tempo entre as trocas de calor e a variação de temperatura entre as extremidades;

$$
\mathrm{k}=(\Delta \mathrm{Q} . \mathrm{L}) /(\mathrm{A} . \Delta \mathrm{t} . \Delta \mathrm{T})
$$

$\mathrm{k}$ - condutividade térmica $(\mathrm{W} /(\mathrm{m}-\mathrm{K})) ; \Delta \mathrm{Q}$ - quantidade de calor transmitido (J); L - espessura unitária da amostra (m); A - seção transversal unitária da amostra $\left(\mathrm{m}^{2}\right) ; \Delta \mathrm{t}$ - intervalo de tempo (s); $\Delta \mathrm{T}$ diferença de temperatura $(K)$, obs.: $1 \mathrm{~W}=1 \mathrm{~J} / \mathrm{s}$.

A condutividade térmica calcula a transferência de calor por condução, entretanto para calcular a transferência de calor levando em conta a convecção deve-se utilizar a transmitância térmica, resultante do inverso da razão entre a espessura total do material e sua condutividade térmica.

$$
\mathrm{U}=1 /(\mathrm{e} / \mathrm{k})
$$

U - transmitância térmica $(\mathrm{W} /(\mathrm{m}-\mathrm{K}))$; e - espessura do material trabalhado $(m) ; \mathrm{k}$ - condutividade térmica do material $(\mathrm{W} /(\mathrm{m}-\mathrm{K}))$.

Observa-se que a composição de cobogós está fundamentada, ainda que intuitivamente, nas características de materiais porosos, pois também estão estruturalmente baseados em uma relação de cheios e vazios. Portanto, para estudar o desempenho térmico do elemento foram definidos três itens de análise que buscam uma relação indireta com as propriedades térmicas dos materiais porosos:

Volume de Vazios ("Porosidade") - Volume de vazios presentes em uma determinada amostra de um sistema vazado, este item possui uma relação mais direta com a propriedade a qual se refere, pois ambas baseiam-se no mesmo cálculo e são medidas em porcentagem;

Velocidade da Ventilação Interna ("Permeabilidade") Velocidade com que o vento percorre o interior de um ambiente que possui um sistema vazado em uma ou mais de suas superfícies externas, medida em $\mathrm{km} / \mathrm{h}$, esta relação com a permeabilidade dá-se pela ideia de que o coeficiente de permeabilidade é proporcional à vazão final do fluido que percorre uma amostra de material;

Temperatura Interna ("Transmitância Térmica") Temperatura medida no interior de um ambiente que possui um sistema vazado em uma ou mais de suas superfícies 
externas, medida em ${ }^{\circ} \mathrm{C}$, esta relação com a transmitância térmica dá-se pela ideia de que a mesma é proporcional à variação de temperatura entre as extremidades de uma amostra de material.

Para analisar o desempenho dos cobogós em função desses itens foi desenvolvido um modelo virtual, utilizando 0 software Rhinoceros 5.0 (McNeel \& Associates), cúbico de $3 \mathrm{~m}$ de lado, com espessuras de paredes e lajes de $20 \mathrm{~cm}$, apresentando sistemas vazados idênticos em duas faces opostas, para garantir equidade de fatores ambientais na análise. Segundo Bittencourt; Cândido (2010), essa simetria é uma condição fundamental para a análise das propriedades em função da porosidade.

"Para construções apresentando aberturas de entrada e saída iguais, a média da velocidade interna de ar é função da porosidade da construção, representada pela razão do total da área aberta dividida pela área da parede, independentemente da direção do vento." (BITTENCOURT; CÂNDIDO, 2010, p. 54).

O desempenho dos cobogós foi simulado através do software CFD 2016 (Autodesk Inc.), tal software pode ser utilizado para análise de condições ambientais de edificações. Para configuração ambiental o software utiliza informações de coordenadas geográficas, data e hora e orientação do modelo. Além de um invólucro no qual são aplicadas as configurações ambientais como, velocidade do vento e temperatura externa.

Para efeito de análise foram determinadas condições ambientais idênticas, baseadas no clima da Cidade do Recife, em todos os modelos, tais como, incidência solar segundo as coordenadas locais, $8^{\circ} 3^{\prime} \mathrm{S}$ e $34^{\circ} 52^{\prime} \mathrm{W}$, data de análise 22/12 (solstício de verão no hemisfério sul), horário de análise de maior intensidade solar $12 \mathrm{~h} 00 \mathrm{~min}$, presença dos sistemas nas fachadas leste e oeste, velocidade do vento a $15 \mathrm{~km} / \mathrm{h}$ (velocidade média do vento em Recife) e temperatura externa de $27^{\circ} \mathrm{C}$ (temperatura média de Recife no verão) APAC (2015).

Para investigar o desempenho de um cobogó com organização voronoi, buscou-se inicialmente compreender as características e desempenhos dos cobogós comerciais:

Cobogó Padrão - Forma mais comum de cobogó, sua estrutura baseia-se na subtração de um grid de vazios sobre uma superfície cheia (Figura 3a);

Cobogó Veneziano - Sistema vazado composto de elementos inclinados para proteção da chuva no interior do ambiente (Figura 3b);
Cobogó Boca de Lobo - Sistema baseado na ideia de peitoril ventilado, possui elementos de proteção invertidos nas faces externas e internas (Figura 3c).

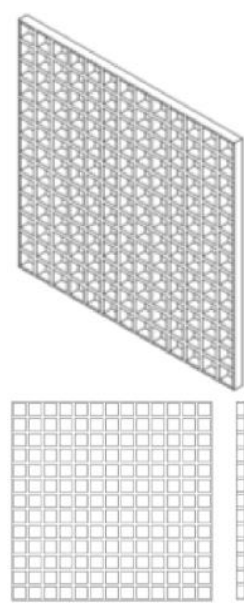

(a)

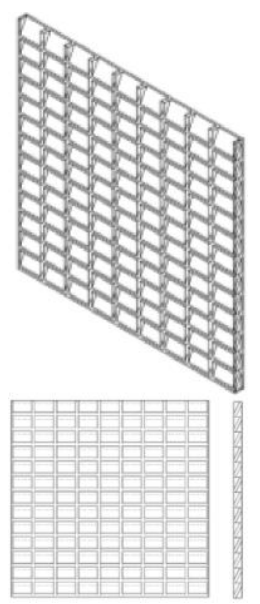

(b)

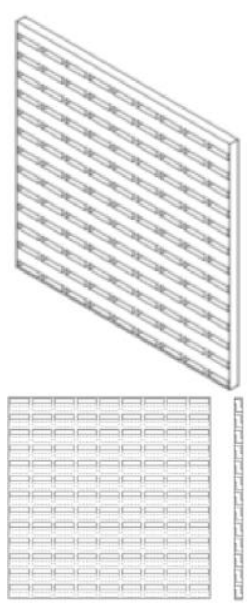

(c)
Figura 3: Representações dos cobogós comerciais.

Fonte: Estudos autorais

Para os cobogós comerciais observam-se os seguintes resultados:

Cobogó Padrão - Este sistema possui volume de vazios de $39 \%$, a velocidade de ventilação interna predominou em $14 \mathrm{~km} / \mathrm{h}$ com poucas variações, isto deve-se à grande abertura deste sistema que permite maior fluidez do vento e uma moderada incidência solar, propiciando a elevação da temperatura interna que pôde chegar, em certos pontos, próxima a $32^{\circ} \mathrm{C}$ (Figura $\left.4 \mathrm{a}\right)$;

Cobogó Veneziano - Este sistema possui volume de vazios de $36 \%$, a velocidade de ventilação interna predominou em $10 \mathrm{~km} / \mathrm{h}$ com variações chegando a $6 \mathrm{~km} / \mathrm{h}$, isto deve-se à composição inclinada do elemento que controla moderadamente 0 acesso da ventilação e diminui a incidência solar direta, permitindo temperaturas internas mais amenas em relação ao sistema anterior, em torno de $27^{\circ} \mathrm{C}$ (Figura 4b);

Cobogó Boca de Lobo - Este sistema possui volume de vazios de $34 \%$, a velocidade de ventilação interna predominou em $8 \mathrm{~km} / \mathrm{h}$ com poucas variações, isto deve-se ao fechamento do sistema que dificulta o acesso da ventilação, mas impede a incidência solar direta, alcançando temperaturas internas similares ao veneziano, em torno de 26으 (Figura 4c). 


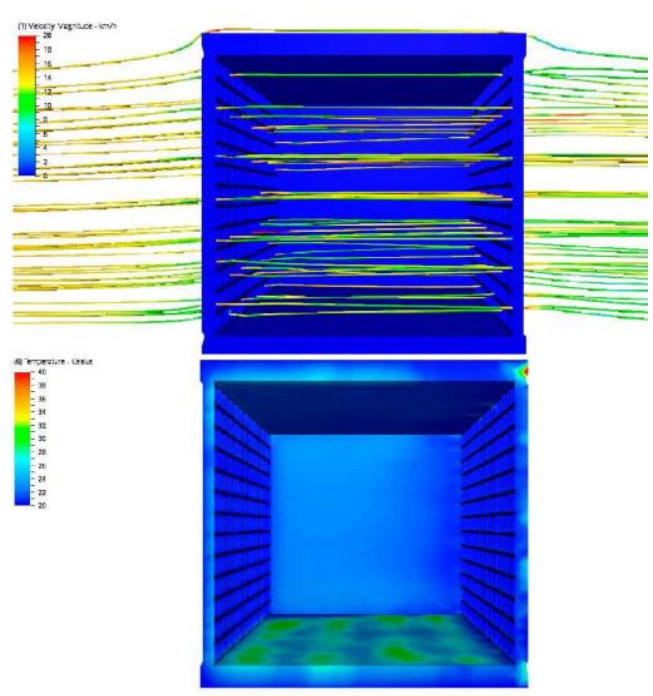

(a)

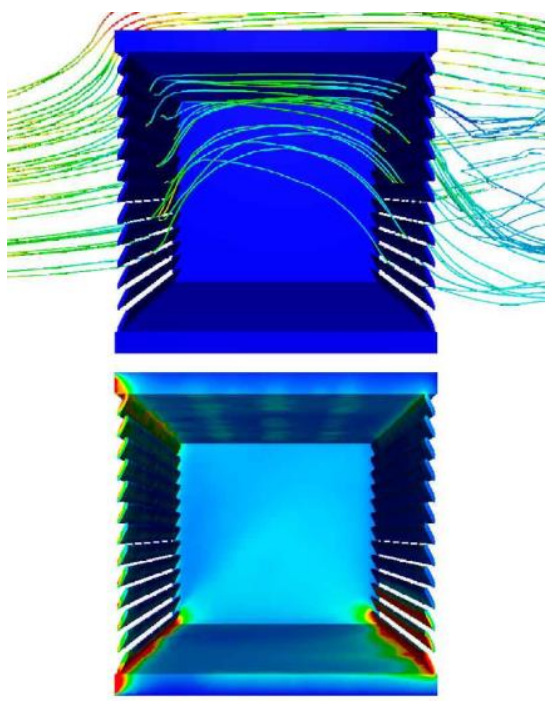

(b)
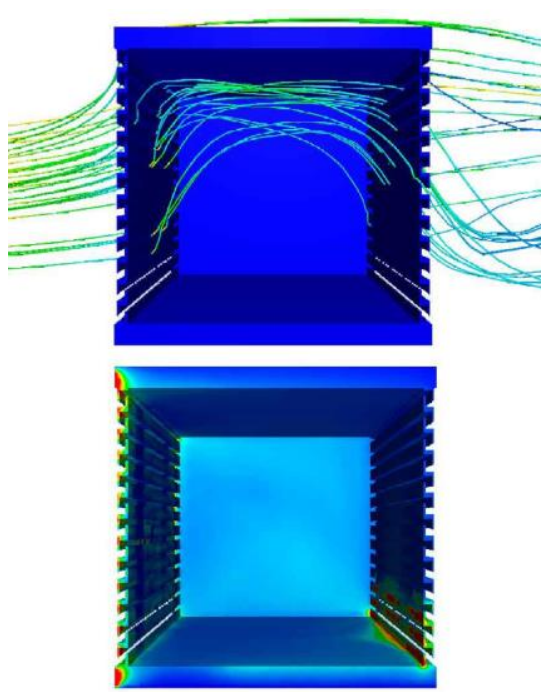

(c)

Figura 4: Análises dos cobogós comerciais.

Fonte: Estudos autorais

Como pode ser visto cada sistema possui suas particularidades e respondem de maneira diferente às mesmas condições ambientais, isso ocorre principalmente pelo modo como os espaços vazios se organizam e dão forma ao sistema, visto que o percentual de volume de vazios possui pouca diferença entre os três sistemas.

Assim, para estudar o desempenho de um cobogó seguindo a lógica de estruturação voronoi da argila, foi desenvolvido um modelo com o mesmo volume de vazios do cobogó padrão, 39\% (Figura 5).
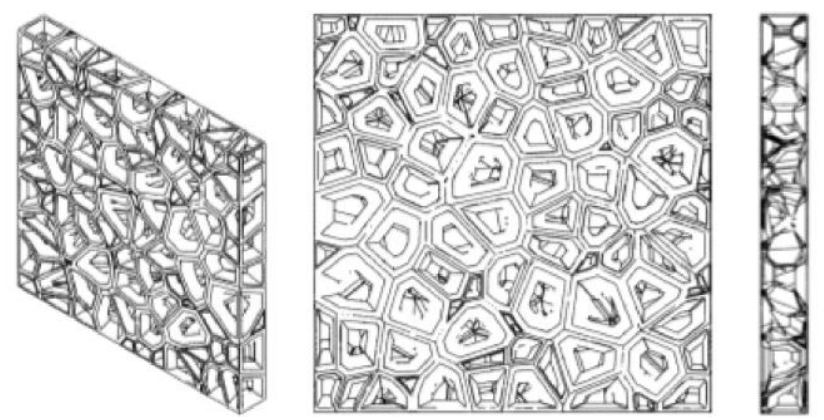

Figura 5: Representações do cobogó voronoi (39\%).

Fonte: Estudos autorais

Em seguida, o mesmo modelo digital construído para análise dos cobogós comerciais foi utilizado para análise do cobogó voronoi, assim como foram definidas as mesmas condições ambientais no CFD 2016 (Autodesk Inc.).

Para o cobogó voronoi (39\%) observam-se os seguintes resultados:
Cobogó Voronoi (39\%) - A tipologia com 39\% de volume de vazios atinge uma velocidade de ventilação interna de $8 \mathrm{~km} / \mathrm{h}$ com variações chegando a $9 \mathrm{~km} / \mathrm{h}$, isto deve-se à organização complexa dos vazios dentro do sistema que cria canalizações da ventilação e permite certo grau de controle da incidência solar direta, apresentando temperaturas internas em torno de $25^{\circ} \mathrm{C}$ (Figura 6).

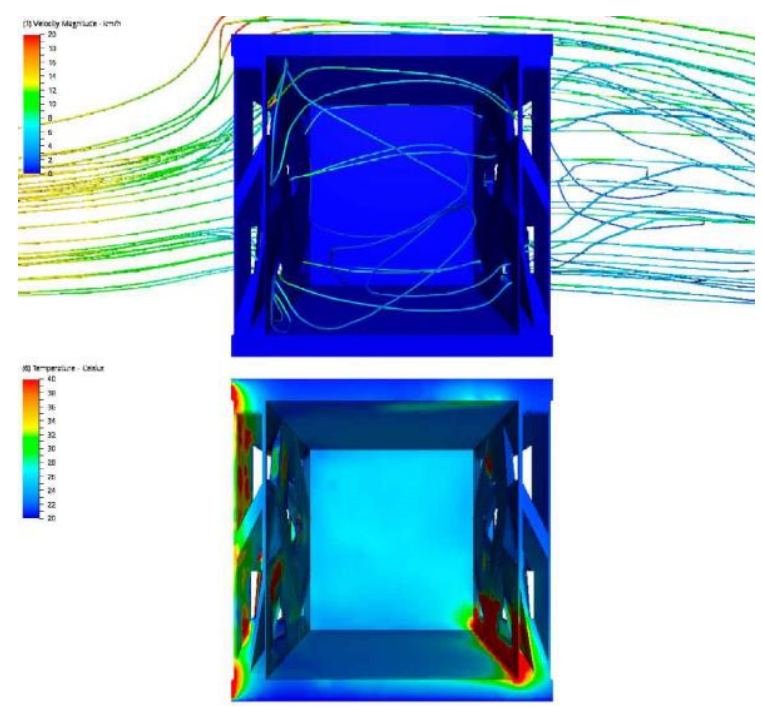

Figura 6: Análises do cobogó voronoi (39\%).

Fonte: Estudos autorais

Percebe-se assim uma ampliação do desempenho térmico com a utilização do sistema voronoi, pois a estruturação complexa de seus vazios potencializa uma proteção da 
incidência solar direta maior que o cobogó padrão e permite uma ventilação no interior da edificação mais intensa que o cobogó veneziano e o boca de lobo. Tal eficiência carece de estudos mais aprofundados e simulações físicas para validar as especulações do experimento.

Baseado nesses resultados, uma estratégia projetual de cobogós de estruturação voronoi foi desenvolvida. Diferente dos padrões comerciais onde as variações de desempenho acontecem pela diferenciação da forma, nesta estratégia é a mudança do volume de vazios que regula tais variações. A ideia é dar ao arquiteto o controle da composição do elemento através da parametrização das necessidades especificas de cada projeto.

Para testar este controle foram desenvolvidos três modelos possuindo volume de vazios de $25 \%, 50 \%$ e $75 \%$, procurouse observar o desempenho dessas variações com a mesma estrutura espacial, assim como as propriedades e condições climáticas das análises anteriores.

Para as variações de cobogó voronoi observam-se os seguintes resultados:

Cobogó Voronoi (25\%) - A tipologia com 25\% de volume de vazios atinge uma velocidade de ventilação interna de $6 \mathrm{~km} / \mathrm{h}$ com variações chegando a $8 \mathrm{~km} / \mathrm{h}$, isto deve-se à presença de aberturas muito pequenas no sistema que permitem a diminuição da temperatura interna, em torno de $24^{\circ} \mathrm{C}$ (Figura 7a);

Cobogó Voronoi (50\%) - A tipologia com 50\% de volume de vazios atinge uma velocidade de ventilação interna de $9 \mathrm{~km} / \mathrm{h}$ com variações chegando a $10 \mathrm{~km} / \mathrm{h}$, percebe-se a influência do aumento no volume de vazios no aumento da velocidade

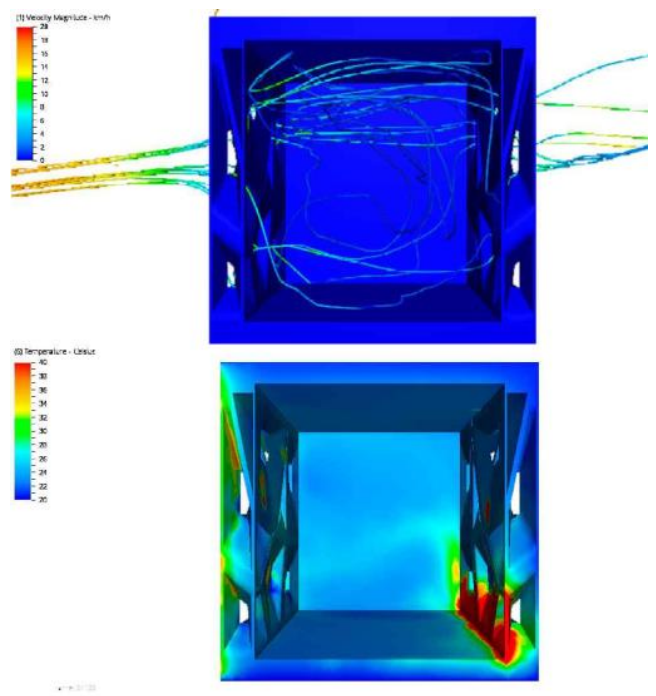

(a)

a)

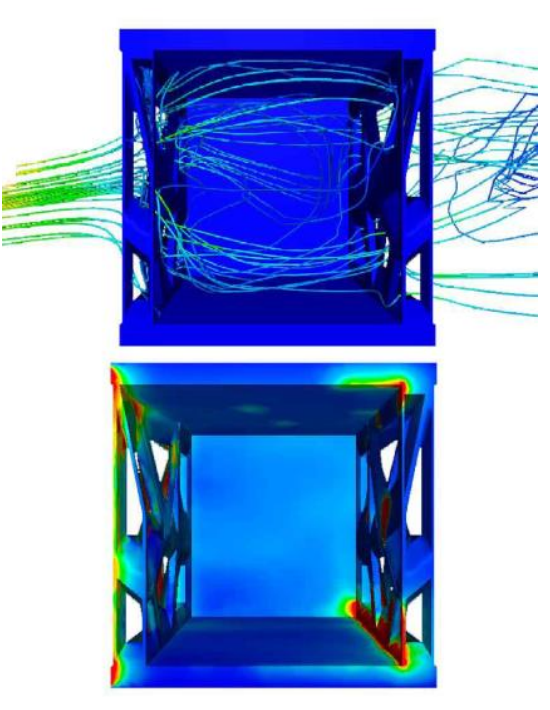

(b) de ventilação, assim como no aumento da temperatura, em torno de $28^{\circ} \mathrm{C}$ (Figura $7 \mathrm{~b}$ );

Cobogó Voronoi (75\%) - A tipologia com 75\% de volume de vazios atinge uma velocidade de ventilação interna de $11 \mathrm{~km} / \mathrm{h}$ com variações chegando a $13 \mathrm{~km} / \mathrm{h}$, já sua temperatura interna predomina em torno de $34^{\circ} \mathrm{C}$. Evidenciando assim, a lógica de aumento da velocidade de ventilação e temperatura com o aumento do volume de vazios (Figura 7c).

As diferentes capacidades térmicas, atingidas pela variação do volume de vazios, podem determinar a utilização de cada sistema em função de especificações climáticas e projetuais, tais como uso do ambiente e orientação da fachada. Assim como há a possibilidade de infinitas variedades de volume de vazios, há também a possibilidade da utilização de percentuais diferentes em células diferentes do mesmo sistema, possibilitando um maior controle na concepção do elemento vazado.

\section{Materialização}

A produção tradicional do cobogó de material cerâmico baseia-se no preenchimento de um molde para obtenção da forma (VIEIRA et al., 2012). Este modelo de fabricação, apesar de permitir uma produção rápida, restringe a possibilidade de variação da forma e determina uma malha regular de composição.

Para a produção de um cobogó de estruturação voronoi este tipo de abordagem não se mostra vantajoso, pois a produção de moldes para preenchimento das formas complexas resultaria em um trabalho extremamente dispendioso e economicamente inviável.

Figura 7: Análises das variações de cobogó voronoi.

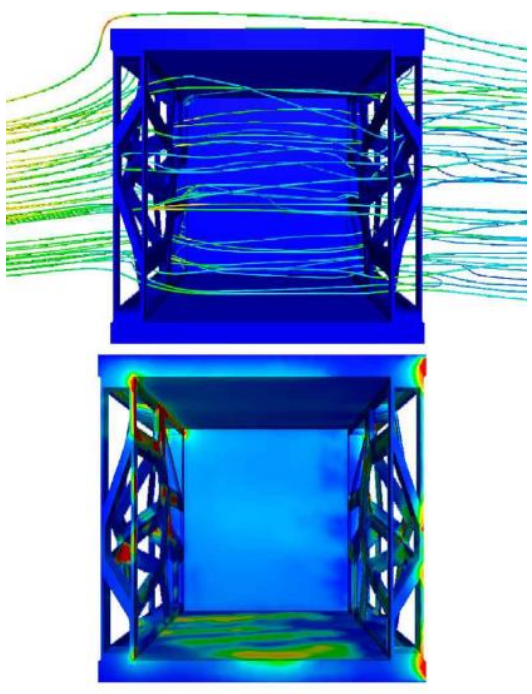

(c)

Fonte: Estudos autorais 
Entretanto, a fabricação aditiva, apresenta-se como uma solução viável para tal produção, pois também se baseia numa lógica de preenchimento para obtenção da forma, dispensando o molde ao utilizar-se de impressoras 3D para realizar a tarefa.

Através desta técnica pode-se viabilizar a fabricação do sistema voronoi de maneira simples, rápida e econômica, facilitando a produção de peças em larga escala, assim como uma alta precisão na geometria das mesmas. O cobogó voronoi pode ser manufaturado por meio de processos de projeto e produção que envolve as seguintes etapas:

Modelagem - Na primeira etapa do processo é feita a modelagem do sistema vazado utilizando o software Rhinoceros 5.0 (McNeel \& Associates) junto ao programa de parametrização Grasshopper 0.9.0076 (Scott Davidson) para controle e decisão das porosidades aplicadas (Figura 8);

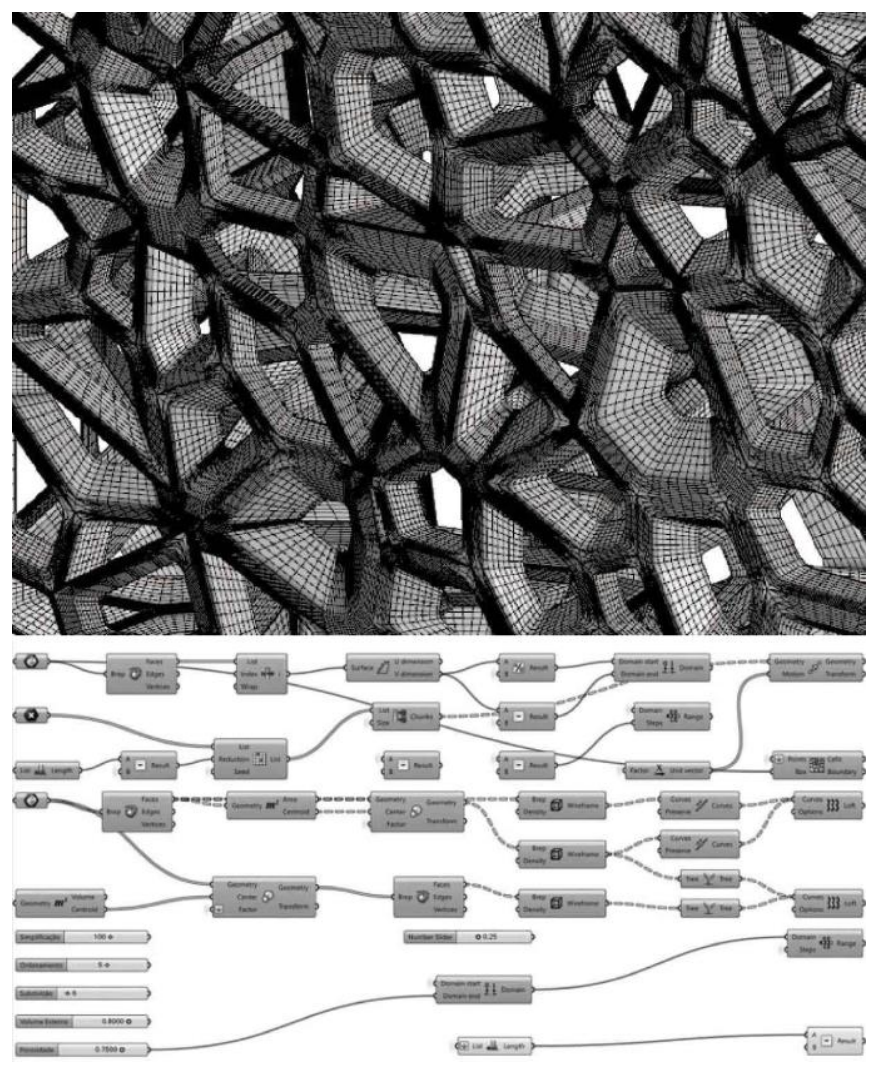

Figura 8: Modelo e código gerador.

Fonte: Estudos autorais

Divisão - Num segundo momento o sistema vazado é divido em partes que possuem encaixe através de juntas metálicas (Figura 9);
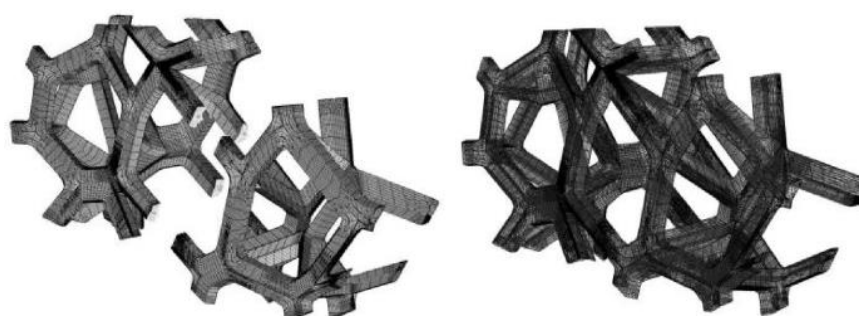

Figura 9: Divisão e encaixe das partes.

Fonte: Estudos autorais

Prototipagem - Após a divisão dos componentes, cada peça é levada para a fabricação através de impressoras 3D (Figura 10);
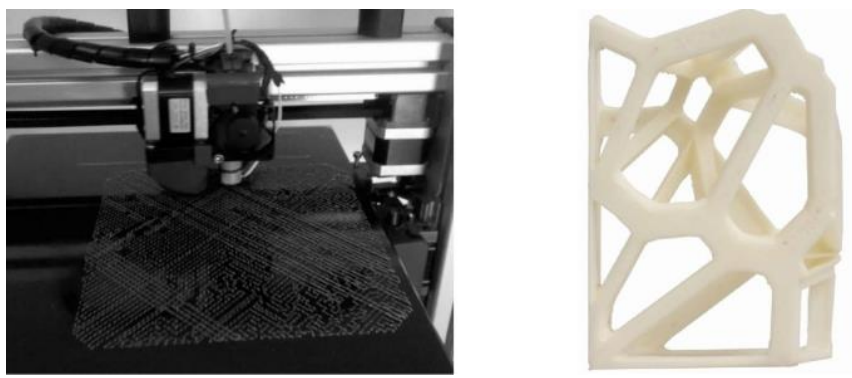

Figura 10: Prototipagem das peças em impresora 3D.

Fonte: Estudos autorais

Montagem - Por último, as peças produzidas são encaixadas montando o sistema vazado originalmente modelado (Figura 11).
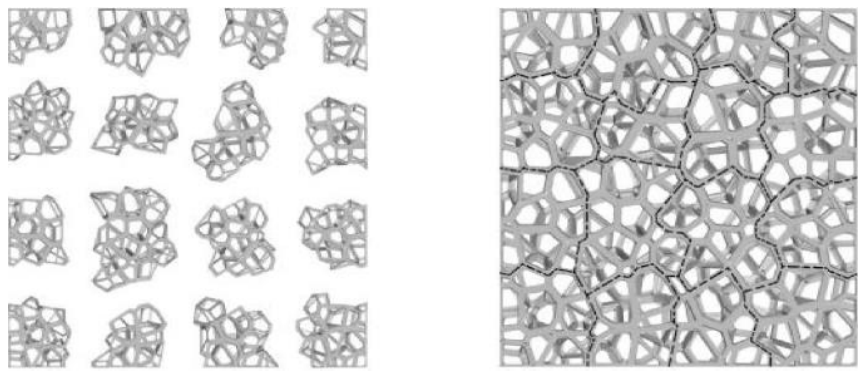

Figura 11: Montagem do sistema vazado.

Fonte: Estudos autorais

Através deste processo podem-se definir os parâmetros de modelagem, produzir e montar uma infinidade de sistemas. Tal processo, entretanto necessita de maior aprofundamento para definir as especificações técnicas de todos os componentes pertinentes ao sistema de montagem. 


\section{Conclusões}

O uso de tecnologias digitais na atualização de estratégias tradicionais de adaptação climática apresentou-se como uma ferramenta para enfrentar problemas contemporâneos. Diversos tipos de abordagens computacionais foram desenvolvidos buscando agregar um valor estético-ambiental a ferramenta.

A computação material apresenta-se como uma forma de alcançar maior integração entre a concepção e a materialidade arquitetônica através da compreensão das propriedades e comportamentos dos materiais para ampliar seus impactos na arquitetura, e pode ser aplicada na concepção de sistemas vazados como alternativa para ampliar seu desempenho térmico, minimizando o problema energético de aparelhos de controle microclimático.

Através do estudo da argila puderam-se perceber relações de desempenho térmico geradas por sua microestrutura interna, permitindo o desenvolvimento de uma metodologia que ampliasse tal efeito na construção.

Embora tenha havido dificuldades técnicas, inerentes ao tempo e estrutura de um trabalho de graduação, para a realização deste trabalho, como a dificuldade de prototipagem em Recife que não permitiu a impressão em cerâmica, sendo todos os estudos de prototipagem feitos em impressoras 3D comuns de PLA, assim como o difícil acesso a equipamentos de tecnologia avançada de aferição das simulações, percebe-se a potencialidade do sistema de cobogó voronoi para responder a condicionantes climáticos e projetuais.

\section{Referências}

ABCERAM (Associação Brasileira de Cerâmica) Informações Técnicas - Definição e Classificação Retrieved from http://www.abceram.org.br/site/index. php?area=4
Ahlquist, S.; Menges, A. (2011). Computational Design Thinking. Londres : Architectural Design.

APAC (Agência Pernambucana de Águas e Climas) Meteorologia Estações do ano Retrieved from http://www.apac.pe.gov.br/meteorologia/estacoes-doano.php?estacao $=$ verao

Bittencourt, L.; Cândido, C. (2010). Ventilação Natural em Edificações. Rio de Janeiro : Convênio ECV033/04 realizado entre ELETROBRAS PROCEL e UFAL.

Frota, A. B.; Schiffer, S. R. (2001). Manual de Conforto Térmico.São Paulo : Studio Nobel

Hensel, M. (2008). Performance-Oriented Design: Precursors and potentials. In Hensel, M.; Menges, A. (Eds.), Versatility and vicissitude (pp. 48-53). Londres : Architectural Design.

Holanda, A. (1976). Roteiro para Construir no Nordeste. Recife : UFPE - MDU.

Menges, A. (2012). Material Computation: Higher integration in morphogenetic design. Londres : Architectural Design.

Menges, A. (2014). Rethinking Materiality Through Computation in Architecture. Palestra realizada na Associação de Arquitetos de Estocolmo. Retrieved from https://www.youtube.com/watch?v=PbgArau_4vl

Oxman, N. (2012). Material Computation. In Sheil, B. Manufacturing the Bespoke: Making and Prototyping Architecture (pp. 256-265). Londres : Architectural Design

Tran, Q.T.; et al. (2009). Reverse k Nearest Neighbor Search on Spatial Networks. In Haumerlain, A.; et al. (Eds.), Transactions on Large-Scale Data and Knowledge Centered Systems (pp. 353-372). Dordrecht : Springer Science and Business Media.

Vieira, A.; et al. (2012). Cobogó de Pernambuco. Recife : Luminar.

Whitaker, S. (1969, December 69). Advances in theory of fluid motion in porous media. Industrial \& Engineering Chemistry, 61(12), 14-28.

W.G., M. (2006). Caracterização Microestrutural da Argila Expandida para Aplicação como Agregado em Concreto Estrutural Leve. Anais do 48ํㅡㄹ Congresso Brasileiro de Cerâmica, 193-199. 